\title{
Insulin in combination with cisplatin induces the apoptosis of ovarian cancer cells via p53 and JNK activation
}

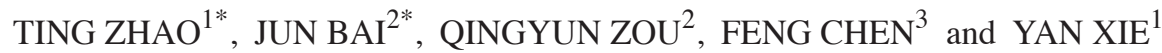 \\ ${ }^{1}$ Department of Obstetrics and Gynecology, Jiading Central Hospital Affiliated Shanghai University of \\ Medicine \& Health Sciences, Shanghai 201800; ${ }^{2}$ Department of Vascular and Endovascular Surgery, \\ Changzheng Hospital Affiliated to The Second Military Medical University, Shanghai 200003; ${ }^{3}$ Department \\ of Obstetrics and Gynecology, Xuzhou Central Hospital, Xuzhou, Jiangsu 221004, P.R. China
}

Received February 4, 2017; Accepted August 7, 2017

DOI: $10.3892 / \mathrm{mmr} .2017 .7752$

\begin{abstract}
Drug resistance is an obstacle to effective treatment of ovarian cancer. There have been substantial evidences supporting the association between diabetes and the sensitivity to chemotherapy. Insulin (INS) is believed to be the strongest, most lasting hypoglycemic drug. Therefore, the present study aimed to elucidate whether insulin could facilitate the anti-proliferative activities of cisplatin (cis-diamminedichloroplatinum, DDP) in the A2780 ovarian cancer cell line. The inhibitory effects of DPP with/without INS on the growth of A2780 cells was measured by MTT assay. The cell cycle stages and levels of apoptosis were determined by flow cytometry. The amounts of signaling elements involved in the regulation of were examined using western blotting and reverse transcription-quantitative polymerase chain reaction analysis. The results indicated that INS pre-treatment enhanced the inhibitory effect of DDP on the proliferation of A2780 cells, and facilitated the apoptosis induced by DDP. INS-DDP treatment led to a marked decrease in the percentage of $G_{0} / G_{1}$ phase cells, but a corresponding increase in the proportion of $\mathrm{S}$ phase cells. Furthermore, A2780 cells pretreated with INS followed by DDP upregulated the protein expression level of phosphorylated c-Jun N-terminal kinase (JNK), which resulted in a substantial increase in the expression levels of p53 mRNA and protein, compared with DDP administration alone. In conclusion, the combination of INS and DDP facilitated the apoptosis of A2780 cells, which may be associated with the activation of the JNK signaling pathway and consequently the involvement of p53 at
\end{abstract}

Correspondence to: Dr Yan Xie, Department of Obstetrics and Gynecology, Jiading District Central Hospital Affiliated Shanghai University of Medicine \& Health Sciences, 1 Chengbei Road, Shanghai 201800, P.R. China

E-mail: 13321843598@163.com

*Contributed equally

Key words: ovarian cancer, insulin, cisplatin, c-Jun N-terminal kinase, p53 both mRNA and protein expression levels. These results may be useful in furthering our understanding of the mechanisms involved in the chemotherapeutic treatment of ovarian cancer.

\section{Introduction}

Ovarian cancer is the sixth most common cancer and the seventh leading cause of cancer-associated mortality in women worldwide (1). Traditionally, patients suffering from the disease are treated by cytoreductive surgery and/or chemotherapy (2). Unfortunately, the past decades have seen little improvement in the survival rate among ovarian cancer patients (3). Challenges in the surgical treatment of ovarian cancer include late detection, tumor metastasis within the peritoneal cavity, drug resistance and cancer recurrence even after initial therapy (4). Therefore, increasing attention has been drawn to the use of chemotherapeutic agents.

As the first-line agent to treat ovarian cancer, cisplatin (cis-diamminedichloroplatinum, DDP) and its platinum derivatives cause DNA interstrand cross-links, which then induces DNA damage responses and the initiation of apoptotic mechanism, and ultimately triggers the death of cancer cells $(5,6)$. However, the continued use of these DNA cross-linking agents fuels the rise of drug resistance, which is difficult to overcome. This issue becomes more troublesome with the presence of glucose tolerance or type II diabetes among cancer patients receiving chemotherapy (7-10). In other words, the sensitivity of cancer patients with diabetes to chemotherapy is reduced (8). As is well known, insulin (INS) is the most effective hypoglycemic drug, which binds to cell surface INS receptor, phosphorylates INS receptor substrates, and in turn mediates a broad spectrum of specific pathways controlling cellular proliferation (10). Recent studies have determined the overexpression of insulin receptor substrates in malignant cells $(7,8)$, while INS can promote the sensitivity of cancer cells to paclitaxel (10). Therefore, possibilities exist that a combined treatment of INS and DPP produce a superior inhibitory effect on the proliferation of ovarian cancer cells, when compared with DPP treatment alone.

Most anti-cancer drugs are designed to perturb cell cycle by inducing/damaging cell cycle events, which activate checkpoints, arrest cancer cells and causes apoptosis (11). The cell 
cycle is a set of coordinated events that take place in a cell and function to integrate various signaling cascades with cell growth and proliferation (12). Cancer cells usually deregulate the cell cycle and undergo unscheduled cell division. Therefore, inhibition of the cell cycle constitutes a potential strategy for therapeutic intervention in cancer therapy $(13,14)$. c-Jun N-terminal kinases (JNKs) are multifunctional kinases involved in different physiological processes. The JNK signal transduction pathway has been demonstrated to serve a crucial role in apoptosis in many cell death paradigms. This kinase, together with tumor suppressor p53, are two apoptosis-regulatory factors frequently involved in the modulation of cancer cell death (15), which may also be signaling components participating in the inhibition of ovarian cancer cell proliferation after the combined therapy of INS and DPP.

The present study demonstrated that the combination of INS and DDP facilitated DDP-induced apoptosis in A2780 cells. The combined therapy resulted in a dramatic decrease in the percentage of $\mathrm{G} 0 / \mathrm{G} 1$ phase cells, but a corresponding increase in the proportion of $\mathrm{S}$ phase cells. These changes could be associated with the activation of the JNK signaling pathway and the involvement of p53 at both mRNA and protein levels.

\section{Materials and methods}

Materials. The A2780 human ovarian cell line was obtained from the China Center for Type Culture Collection (Wuhan, China). Insulin, Dulbecco's modified Eagle's medium (DMEM) and fetal bovine serum (FBS) were purchased from Life Technologies; Thermo Fisher Scientific, Inc. (Waltham, MA, USA). Annexin V-fluorescein isothiocyanate (FITC), penicillin, streptomycin, 3-(4,5-dimethylthiazol-2-yl)-2,5-diphenyltetrazolium bromide (MTT), 2-(4-amidinophenyl)-6-indolecarbamidine dihydrochloride (DAPI), propidium iodide (PI), RNase A and dimethyl sulfoxide (DMSO) were purchased from Sigma-Aldrich (Merck KGaA, Darmstadt, Germany). Cis-platinum (DDP) was from Anji Haosen Pharmaceutical Co., Ltd. (Huzhou, China). Antibodies against phosphorylated (p)-JNK (\#9255) and JNK (\#9252) were bought from Cell Signaling Technology, Inc. (Danvers, MA, USA). Antibodies against $\beta$-actin (sc-47778) and p53 protein (sc-47698) were purchased from Santa Cruz Biotechnology, Inc. (Dallas, TX, USA). Horseradish peroxidase (HRP)-conjugated secondary antibodies for detection of rabbit (A0208) and mouse (A0216) primary antibodies and an enhanced chemiluminescence (ECL) western blotting detection system were purchased from Beyotime Institute of Biotechnology (Nantong, China).

Cell culture. A2780 cells were cultured in DMEM supplemented with $10 \% \mathrm{FBS}, 1 \%$ penicillin and $1 \%$ streptomycin at $37^{\circ} \mathrm{C}$ in a humidified atmosphere of $95 \%$ air $/ 5 \% \mathrm{CO}_{2}$. During the experiments, the cells used were in the exponential growth phase, while culture media were replaced every 2 or 3 days.

Colorimetric MTT assay. The compound MTT was adopted to assess cell proliferation as previously described (16). Briefly, A2780 cells were seeded into 96 -well plates at a density of $2 \times 10^{3}$ cells per well in quintuplicate for $24 \mathrm{~h}$ before exposure to different concentrations of DDP $(0,5,10,15,20,25$ or $30 \mu \mathrm{g} / \mathrm{ml})$, INS $(0,1,2,5,10$, or $15 \mathrm{mU} / \mathrm{ml})$ or both as described above. After incubation for another $24 \mathrm{~h}, 20 \mu 15 \mathrm{mg} / \mathrm{ml} \mathrm{MTT}$ was added to each well and the cells were incubated at $37^{\circ} \mathrm{C}$ for another $4 \mathrm{~h}$. Subsequently, the media was discarded followed by the addition of $150 \mu \mathrm{l}$ DMSO per well to dissolve purple precipitate. The absorbance (A) was measured at $570 \mathrm{~nm}$ using a plate microreader. The cell growth inhibitory rate (I\%) was calculated according to the following equation: inhibitory rate $\%=\left(\mathrm{A}_{\text {control }}-\mathrm{A}_{\text {sample }}\right) /\left(\mathrm{A}_{\text {control }}-\mathrm{A}_{\text {blank }}\right) \times 100 \%$, where $\mathrm{A}_{\text {control }}$ is the absorbance of the untreated cells, $A_{\text {sample }}$ is the absorbance of the cells exposed to DDP, INS or both, and $\mathrm{A}_{\text {blank }}$ is the absorbance of the media.

DAPI staining. A2780 cells were seeded into 6-well plates at a density of $5 \times 10^{4}$ cells per well and incubated at $37^{\circ} \mathrm{C}$ for $24 \mathrm{~h}$. Subsequently, the cells were fixed with $4 \%$ formaldehyde in PBS containing 4\% sucrose at room temperature for $15 \mathrm{~min}$. After washing with PBS three times, the cells were stained using $10 \mu \mathrm{g} / \mathrm{ml}$ DAPI in the dark at room temperature for $15 \mathrm{~min}$. The solution was then removed and the cells were washed with PBS twice. Images were observed under an Olympus X81 microscope (Olympus Corporation, Tokyo, Japan) and analyzed by MetaMorph ${ }^{\circledR}$ Microscopy Automation \& Image Analysis Software (Molecular Devices, LLC, Sunnyvale, CA, USA).

Apoptosis assay. A2780 cells (10\%/well) were incubated in 24-well plates. After treatment, the cells were collected and resuspended in $500 \mu \mathrm{l}$ binding buffer to reach a density of $2 \times 10^{6}$ cells $/ \mathrm{ml}$. The resultant samples were treated with $5 \mu 1$ Annexin V-FITC and $5 \mu \mathrm{l}$ PI in the dark at room temperature for $15 \mathrm{~min}$ before flow cytometry analysis (Miltenyi Biotec $\mathrm{GmbH}$, Bergisch Gladbach, Germany) using CellQuest ${ }^{\mathrm{TM}}$ version 3.3 (BD Biosciences, San Jose, CA, USA).

Cell cycle analysis. Cell cycle stages were determined by PI staining with flow cytometry. Briefly, after treatment, the cells (at $\sim 1 \times 10^{6}$ cells per group) in triplicate were harvested through centrifugation at $300 \mathrm{xg}$ for $5 \mathrm{~min}$ at $4^{\circ} \mathrm{C}$, followed by washing with ice-cold PBS. Following this, the cells were resuspended in $70 \%$ pre-cooled ethanol and fixed at $4{ }^{\circ} \mathrm{C}$ overnight. Next, the fixed cells were washed with PBS and incubated with RNase A and PI at $37^{\circ} \mathrm{C}$ in the dark for $30 \mathrm{~min}$. DNA content was quantified by flow cytometry analysis.

Western blotting analysis. After measurement of protein concentrations using an Enhanced BCA Protein Assay kit (Beyotime Institute of Biotechnology), the obtained lysates (20 $\mu \mathrm{g} /$ well) were subjected to 4-10\% SDS-PAGE and subsequently blotted to polyvinylidene difluoride membranes (Bio-Rad Laboratories, Inc., Hercules, CA, USA) before incubation at $4{ }^{\circ} \mathrm{C}$ overnight using the following primary antibodies: p-JNK (1:500), JNK (1:1,000), $\beta$-actin $(1: 3,000)$ and p53 (1:500). The membranes were then incubated with HRP-conjugated secondary antibodies $(1: 1,000,1 \mathrm{~h}$, room temperature) and visualized using an ECL detection system. Optical densities of the blots were measured using ImageJ version 1.47 (National Institutes of Health, Bethesda, MD, USA). 
Reverse transcription-quantitative polymerase chain reaction (RT-qPCR). According to the manufacturer's protocol, total RNA was isolated from cells and reverse transcribed with oligo (dT) primers by Takara Mini BEST Universal RNA Extraction kits (Takara Biotechnology Co., Ltd., Dalian, China) with on column RNase-free DNase I treatment (Takara Biotechnology Co., Ltd.). Samples were run on the Light Cycler R 480 system (Roche Diagnostics GmbH, Mannheim, Germany) using SYBR Premix Ex Taq (Takara Biotechnology, Co., Ltd.) according to the manufacturer's protocol. The cycling conditions were as follows: $95^{\circ} \mathrm{C}$ for $2 \mathrm{~min}$, followed by 40 cycles of $95^{\circ} \mathrm{C}$ for $20 \mathrm{sec}, 56^{\circ} \mathrm{C}$ for $1 \mathrm{~min}$ and $72^{\circ} \mathrm{C}$ for $30 \mathrm{sec}$. All values were normalized to GAPDH expression and data were analyzed using the $2^{-\Delta \Delta \mathrm{Cq}}$ method (16). Primer sequences (Sangon Biotech Co., Ltd., Shanghai, China) were as follows: p53 5'-CCTGTCATCTTCTGTCCCTT-3' (forward) and 5'-GGGAGTAGGTGCAAGTCA-3' (reverse); p21 5'-GCG GAACAAGGAGTCAGACAT-3' (forward) and 5'-CCCAAT ACTCCAAGTACACTAAGCA-3' (reverse); GAPDH 5'-TCA ACTACATGGTTTACATGTTC-3' (forward) and 5'-GATCTC GCTCCTGGAAGAT-3' (reverse).

Statistical analysis. All data in the different experimental groups are expressed as the mean \pm standard deviation. Differences between the groups were assessed by one-way analysis of variance followed by the Student-Newman-Keuls, least-significant difference (for equal variances) or Dunnett T3 (unequal variances) multiple comparisons. $\mathrm{P}<0.05$ was considered to indicate a statistically significant difference.

\section{Results}

Effects of DDP and INS on the proliferation of A2780 cells. MTT assay demonstrated that the proliferation of A2780 cells was systemically inhibited with the rise of DDP concentrations from $0.3-30 \mu \mathrm{g} / \mathrm{ml}$ after $24 \mathrm{~h}$ of treatment (Fig. 1A). Notably, the inhibitory effect became significant when the cells were exposed to $3 \mu \mathrm{g} / \mathrm{ml}$ DDP. Therefore, such a concentration was used throughout the following experiments. With respect to the presence of impaired glucose tolerance or type II diabetes in patients receiving DDP-based chemotherapy who may also receive INS, the anti-proliferative effects of INS in combination with DDP on A2780 cells were measured by MMT. In the assay, the cells were administrated with various concentrations of INS $(0,1,2,5,10,15$ and $20 \mathrm{mU} / \mathrm{ml})$ for $6 \mathrm{~h}$ before treatment with $3 \mu \mathrm{g} / \mathrm{ml}$ DDP for $24 \mathrm{~h}$. The results suggested that pre-exposure to INS could cause an increase in the inhibitory rate of A2780 cell proliferation due to administration of $3 \mu \mathrm{g} / \mathrm{ml} \mathrm{DDP,} \mathrm{with} \mathrm{the}$ most substantial impact at $5 \mathrm{mU} / \mathrm{ml}$ (Fig. 1B).

INS facilitates DDP-induced apoptosis. To investigate the possible influence of INS on DDP-induced apoptosis, nuclear changes of A2780 cells were observed using DAPI stating under a fluorescence microscope. As presented in Fig. 2A, fewer normal nuclei but more 'ghost nuclei' were observed in the INS and DDP combination group, compared with the cells treated with INS or DDP alone. The cell apoptotic rate was increased in the DDP and INS+DDP groups, compared with the control and INS groups (Fig. 2B). The same results were determined by flow cytometry analysis (Fig. 2C and D).
A

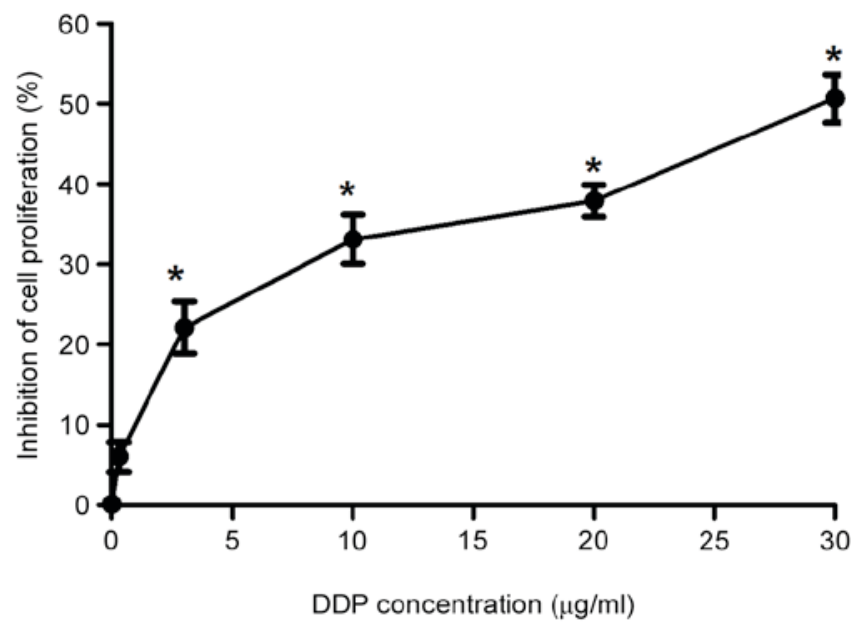

B

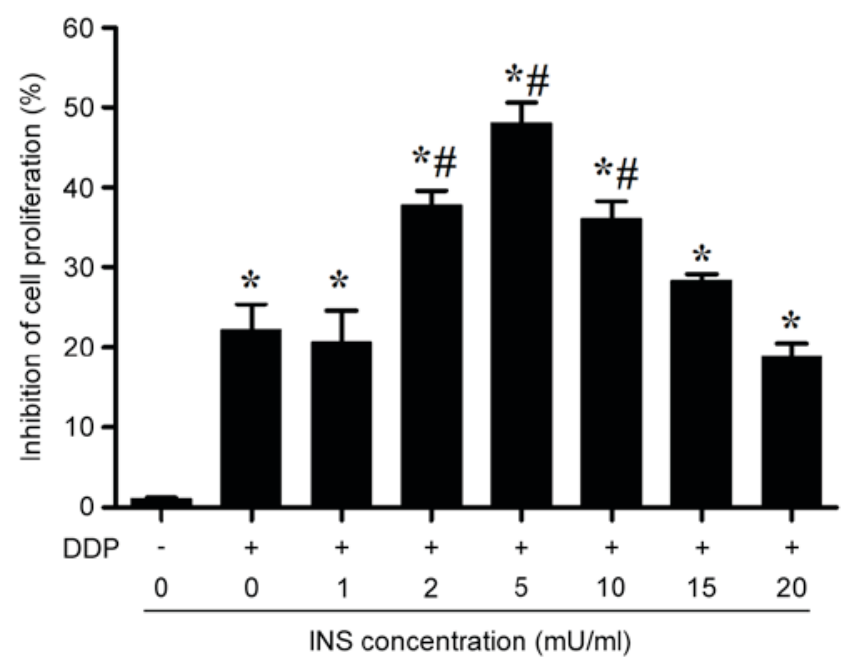

Figure 1. Effects of DDP with/without INS on the proliferation of A2780 cells. (A) Inhibitory effects of DDP on the proliferation of A2780 cells after $24 \mathrm{~h}$ of treatment. (B) Inhibition of DDP and INS combination on the proliferation of A2780 cells. The cells were treated with various concentrations of insulin for $6 \mathrm{~h}$ before exposure to $3 \mu \mathrm{g} / \mathrm{ml}$ DDP for $24 \mathrm{~h}$. Data are presented as the mean \pm standard deviation $(n=4) .{ }^{*} \mathrm{P}<0.05$ vs. control group; ${ }^{\#} \mathrm{P}<0.05$ vs DDP group. INS, insulin; DDP, cis-diamminedichloroplatinum.

Cell cycle arrest. To further determine the mechanism by which INS heightens the sensitivity of A2780 cells to DDP, the cell cycle stages of both treated and normal cells were examined by flow cytometry. The results demonstrated that compared with the control group, administration of DDP alone significantly induced G0/G1-phase accumulation, with a visible reduction in the number of $S$ phase cells (Fig. 3). However, INS-DDP treatment brought in a marked decrease in the percentage of G0/G1 phase cells, but a corresponding increase in the proportion of S phase cells (Fig. 3).

To further verify the impact of the INS on cell cycle, the expression of the cell cycle-associated p21 gene was examined. As presented in Fig. 4A, increased expression levels of p21 mRNA were examined in the DDP groups. In contrast, reduced amounts of p21 mRNA were observed when the 
A

INS

DDP
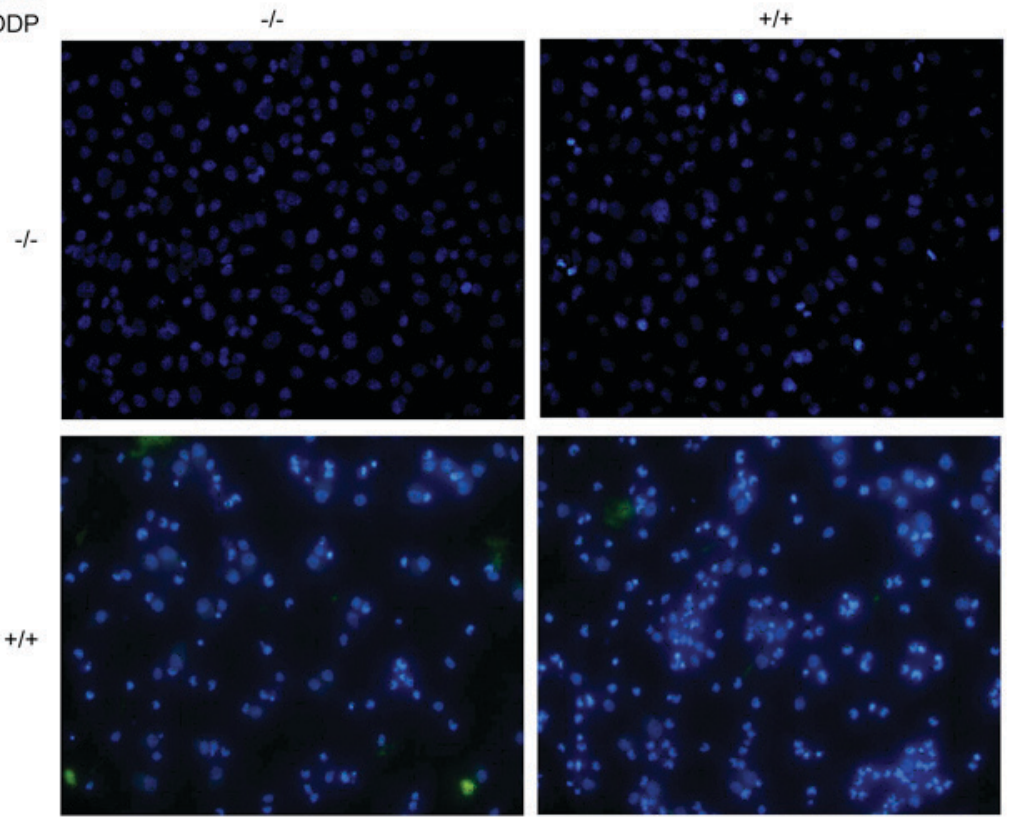

B

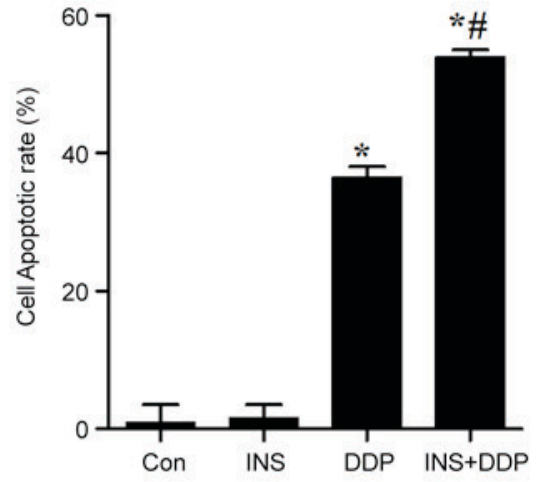

C
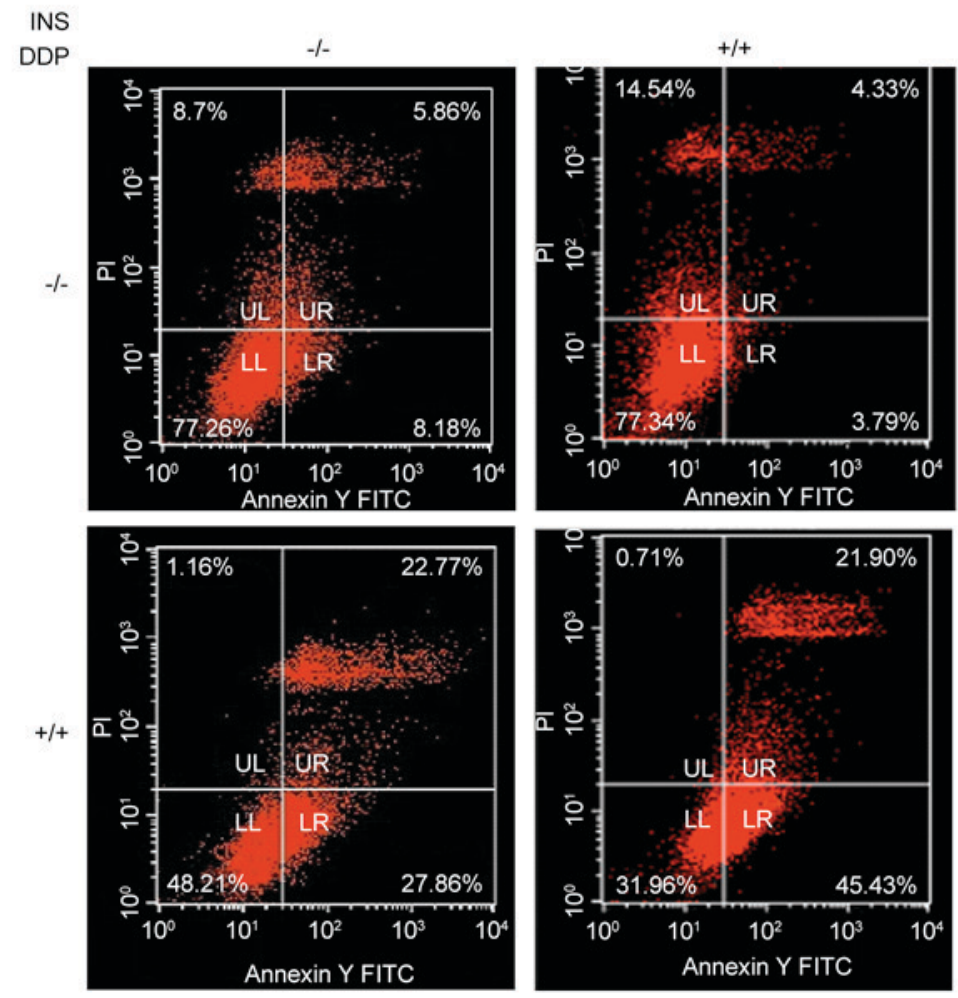

D

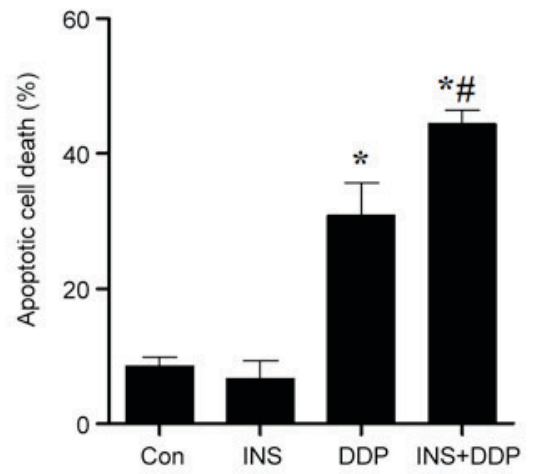

Figure 2. INS facilitates DDP-induced apoptosis in A2780 cells. (A) Representative images (magnification, x200) and (B) statistical analysis of DAPI staining of A 2780 cells after treatment with $5 \mathrm{mU} / \mathrm{ml}$ INS for $6 \mathrm{~h}$ followed by exposure to $3 \mu \mathrm{g} / \mathrm{ml} \mathrm{DDP}$ for $24 \mathrm{~h}$. (C) Representative images and (D) statistical analysis of apoptotic A2780 cells after treatment with $5 \mathrm{mU} / \mathrm{ml} \mathrm{INS}$ for $6 \mathrm{~h}$ followed by exposure to $3 \mu \mathrm{g} / \mathrm{ml} \mathrm{DDP}$ for $24 \mathrm{~h}$, as assessed by flow cytometry. Data are presented as the mean \pm standard deviation $(\mathrm{n}=4)$. ${ }^{*} \mathrm{P}<0.05$ vs. control group; ${ }^{*} \mathrm{P}<0.05$ vs. DDP group. INS, insulin; DDP, cis-diamminedichloroplatinum; Con, control.

cells were pre-exposed to INS followed by DDP administration, compared with DDP treatment alone. In other words, INS-DDP administration could cause cell cycle redistribution compared with DDP treatment alone.
Effects of DDP and INS on the JNK-p53 signaling pathway in A2780 cells. The role of JNK signaling in cancer progression remains unclear. This signaling cascade can be attributed to both tumor-promoting and tumor-suppressing functions. 
A

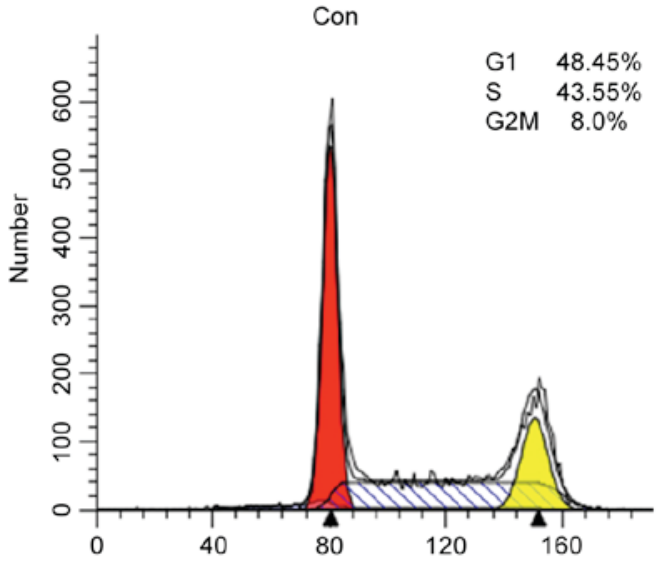

C

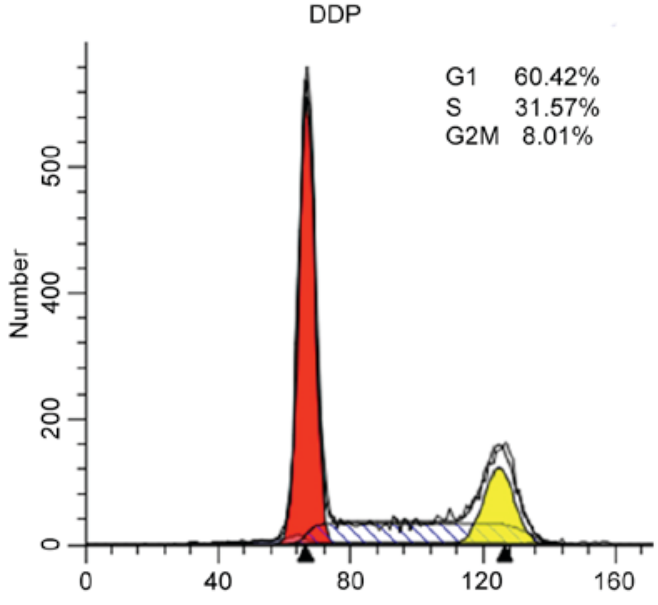

B

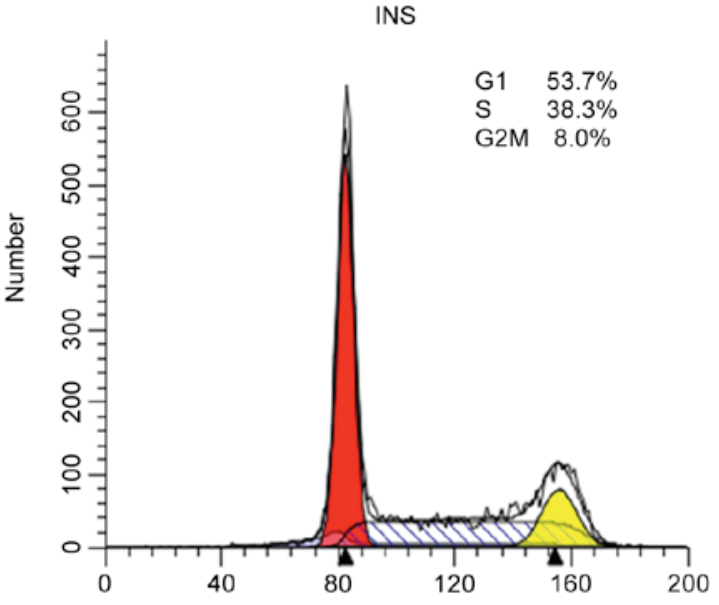

D

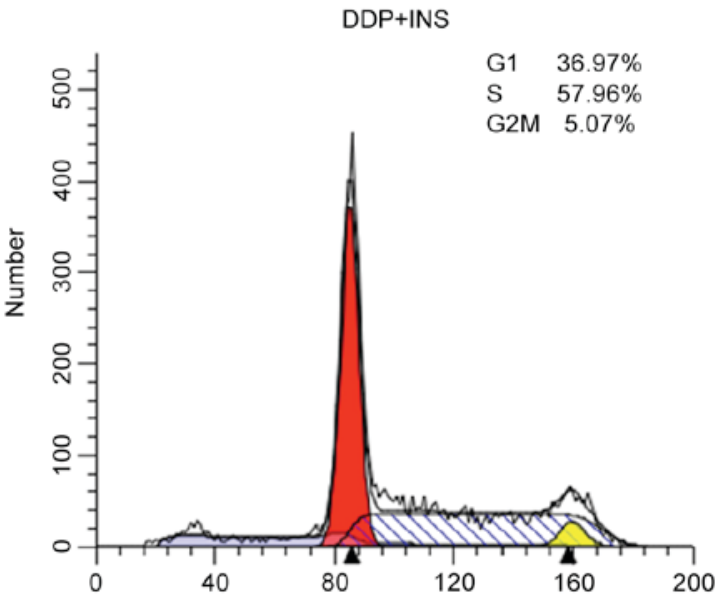

E

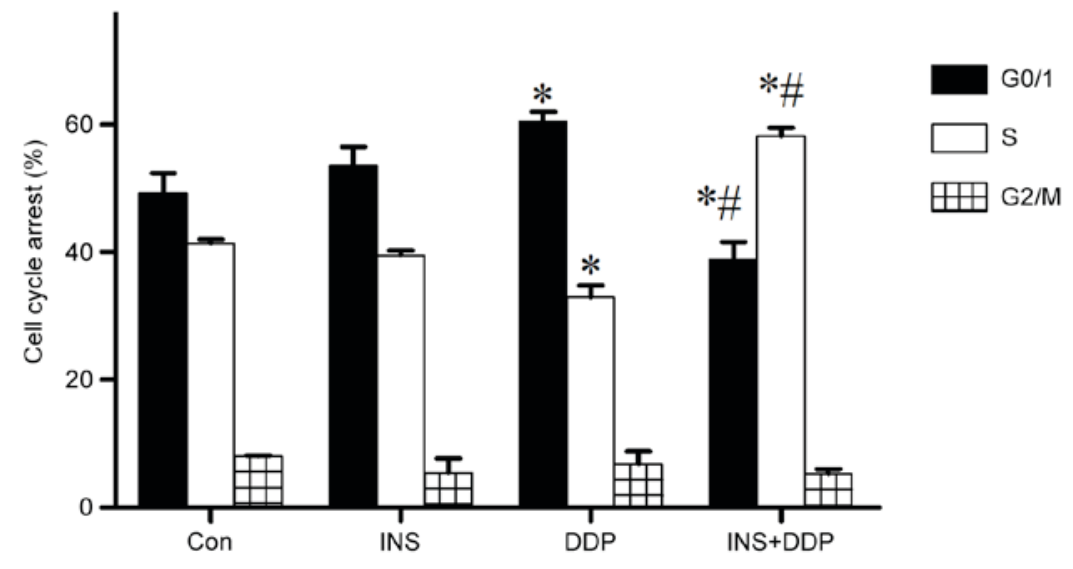

Figure 3. Determination of cell cycle phrases by flow cytometry. Representative flow cytometry images of A2780 cells in the (A) control, (B) INS, (C) DDP and (D) DDP+INS groups after treatment with $5 \mathrm{mU} / \mathrm{ml}$ INS for $6 \mathrm{~h}$ followed by exposure to $3 \mu \mathrm{g} / \mathrm{ml}$ DDP for $24 \mathrm{~h}$. (E) Percentage cell cycle arrest. Data are presented as the mean \pm standard deviation $(\mathrm{n}=4)$. ${ }^{*} \mathrm{P}<0.05$ vs. control group; ${ }^{\sharp} \mathrm{P}<0.05$ vs. DDP group. INS, insulin; DDP, cis-diamminedichloroplatinum; Con, control.

Previous studies have reported that, under a stress state, JNK phosphorylates p53 protein, inhibiting its degradation and consequently promoting cell apoptosis $(4,17)$. The expression of p53 mRNA in A2780 cells was measured by RT-qPCR. The results indicated that DDP treatment could significantly up-regulate the levels of p53 mRNA compared with the control. In contrast, increased amounts of p53 mRNA were determined when the cells were pre-exposed to INS followed by DDP administration, compared with DDP treatment alone (Fig. 4B). 
A

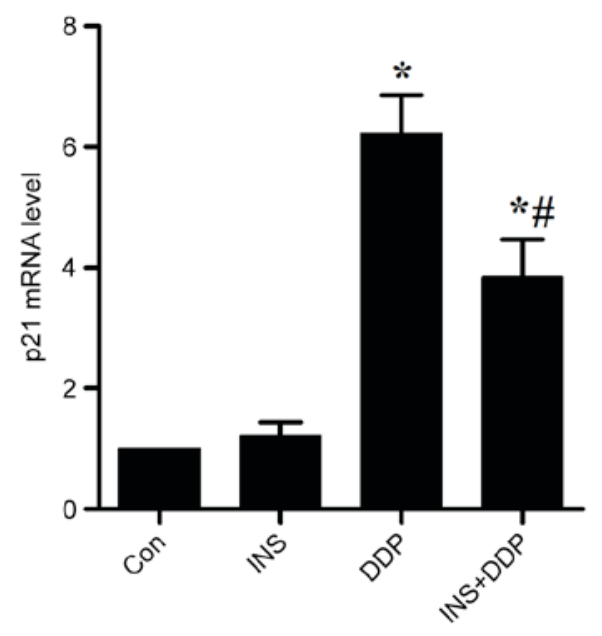

C
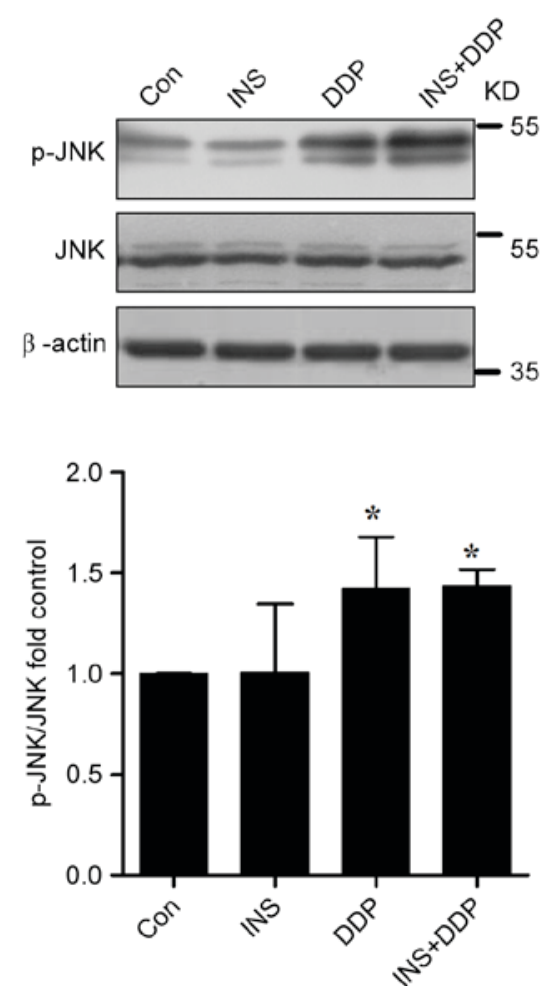

B

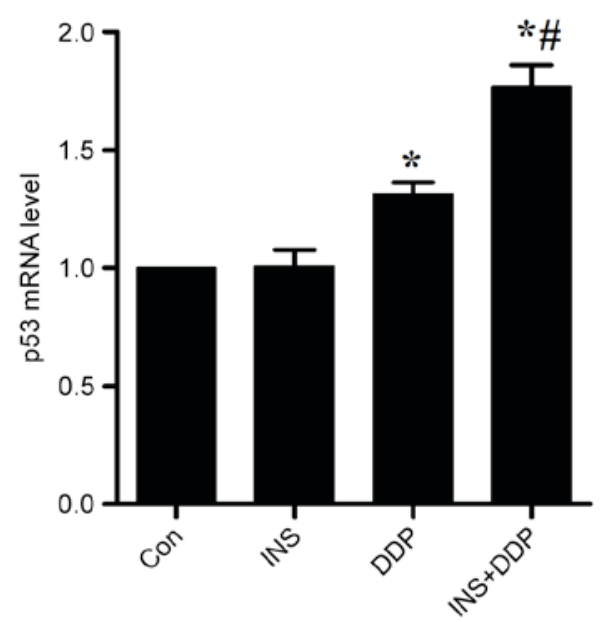

D
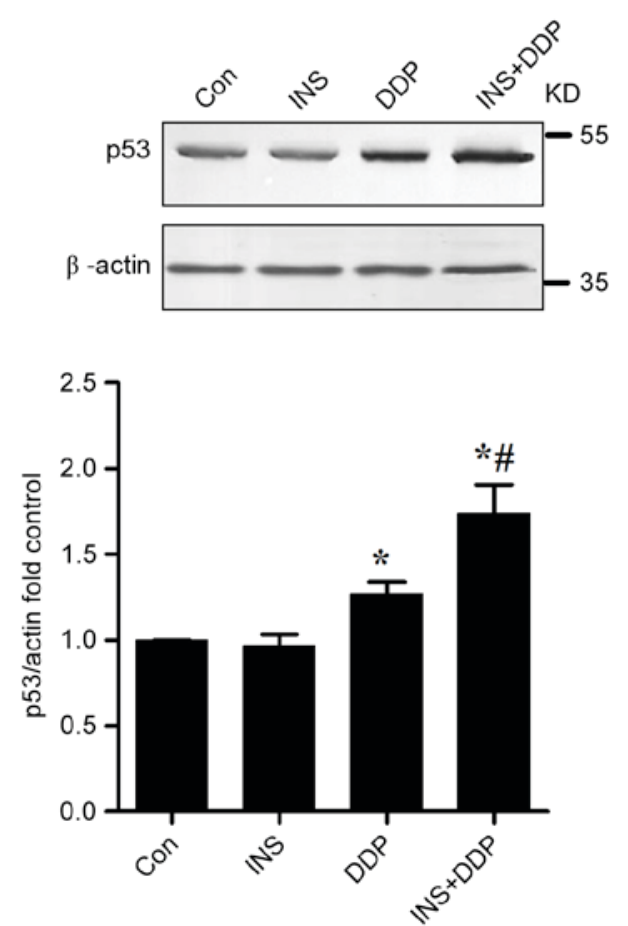

Figure 4. p21, p53 and p-JNK expression levels in A2780 cells in response to treatment with INS and/or DDP. mRNA expression levels of (A) p21 and (B) p53. Protein expression levels of (C) JNK, p-JNK and (D) p53. Data are presented as the mean \pm standard deviation ( $\mathrm{n}=4$ ). ${ }^{\text { }} \mathrm{P}<0.05$ vs. control group; ${ }^{*} \mathrm{P}<0.05$ vs. DDP group. INS, insulin; DDP, cis-diamminedichloroplatinum; Con, control; JNK, c-Jun N-terminal kinase; p-, phosphorylated.

As presented in Fig. 4C, increased quantities of p-JNK were observed in both the DDP and INS-DDP groups compared with the control and INS groups. The p53 protein functions in the checkpoints that arrest human cells in G1/S, S or G2/M phases. According to western blotting, in comparison with the control, the expression levels of p53 in A2780 cells exposed to DDP were substantially increased, which were further elevated after INS-DDP administration (Fig. 4D).

\section{Discussion}

In the current study, INS in combination with DDP facilitated DDP-induced apoptosis in A2780 cells through activation of
JNK, which was in accordance with previous reports (17-19). This combined administration also upregulated the mRNA and protein expression levels of p53 compared with DDP treatment alone, which may then activate other cell cycle checkpoint factors and result in cell cycle redistribution.

Apoptosis is the key to understanding some malignant diseases. A failure in apoptosis can lead uncontrolled triggering of programmed cell death, which is considered as one of the hallmarks of cancer (20). Therefore, activation of apoptosis signaling pathways is a potential mechanism for cancer therapeutic targets, including chemotherapy $(3,4,19)$. DDP, one of the chemotherapy drugs commonly used to treat ovarian cancer, can kill tumor cells mainly through inducing DNA 
damage and activating apoptosis-associated signaling pathways, which finally leads to cell apoptosis $(6,7)$. In the present study, administration of DDP could significantly inhibit the proliferation of A2780 cells in a dose-dependent manner and cause cell apoptosis. In contrast, exposure to both INS and DDP resulted in a higher inhibitory rate of A2780 cell proliferation and facilitated apoptosis. Treating with higher concentrations of INS results in a lower inhibitory rate. This kind of insulin resistance may be because insulin increases the bioactivity of insulin-like growth factor 1 (IGF-I) which appear to have a role in tumor initiation (21). Circulating IGF-1 and IGF-2 bind to the IGF-1 receptor and trigger a signal transduction cascade that leads to increased proliferation and enhanced survival of IGF-responsive cells (22).

The cell cycle is a series of events that take place in a cell leading to its division and duplication (8). Regulation of the cell cycle involves processes crucial to the survival of a cell $(9,10)$. According to the present study, a significant accumulation of cells in G0/G1 phase and a visible reduction in $S$ phase were observed in DDP-treated A2780 cells. However, INS-DDP treatment brought in a dramatic decrease in the percentage of G0/G1 phase cells, but a corresponding increase in the proportion of S phase cells, which means DDP-INS administration may redistribute the cell cycle compared with DDP treatment alone.

Many anticancer drugs target the cell cycle through different signaling pathways and function through activating cell cycle checkpoints and blocking cell division (8). Among these signaling components involved is JNK, which under a stress state can phosphorylate $\mathrm{p} 53$ protein, inhibiting its degradation and consequently promoting cell apoptosis $(4,17)$, especially arresting human cells in G1/S, S or G2/M phases $(11,23,24)$. Increased amounts of $\mathrm{p}-\mathrm{JNK}$ were measured both the DDP and INS-DDP groups. The quantities of p53 mRNA and protein in A2780 cells exposed to DDP were substantially increased, which were further elevated after INS-DDP administration. Although a drug may not possess a particular effect, it may induce the tissues or receptors to respond to a different drug; a process that is known as sensitization. In the present study, INS served a role in chemotherapeutic sensitization within A2780 cells; this effect may be related to appropriate dosage and action time. Therefore, INS may be useful as an adjuvant chemotherapy to reduce DDP dosage, this would result in the ability to alleviate the toxicity and side effects, and to improve the life quality of the patients.

\section{References}

1. Seeber LM and Van Diest PJ: Epigenetics in ovarian cancer. Methods Mol Biol 863: 253-269, 2012.

2. Meyerhardt JA, Catalano PJ, Haller DG, Mayer RJ, Macdonald JS, Benson AB III and Fuchs CS: Impact of diabetes mellitus on outcomes in patients with colon cancer. J Clin Oncol 21: 433-440, 2003.

3. Papa V, Pezzino V, Costantino A, Belfiore A, Giuffrida D, Frittitta L, Vannelli GB, Brand R, Goldfine ID and Vigneri R: Elevated insulin receptor content in human breast cancer. J Clin Invest 86: 1503-1510, 1990.
4. Belfiore A: The role of insulin receptor isoforms and hybrid insulin/IGF-I receptors in human cancer. Curr Pharm Des 13: 671-686, 2007.

5. Bartucci M, Morelli C, Mauro L, Andò S and Surmacz E: Differential insulin-like growth factor I receptor signaling and function in estrogen receptor (ER)-positive MCF-7 and ER-negative MDA-MB-231 breast cancer cells. Cancer Res 61: 6747-6754, 2001

6. Miglietta A, Panno ML, Bozzo F, Gabriel L and Bocca C: Insulin can modulate MCF-7 cell response to paclitaxel. Cancer Lett 209: 139-145, 2004

7. Zou K, Ju JH and Xie H: Pretreatment with insulin enhances anticancer functions of 5-fluorouracil in human esophageal and colonic cancer cells. Acta Pharmacol Sin 28: 721-730, 2007.

8. Hellawell GO, Turner GD, Davies DR, Poulsom R, Brewster SF and Macaulay VM: Expression of the type 1 insulin like growth factor receptor is up-regulated in primary prostate cancer and commonly persists in metastatic disease. Cancer Res 62: 2942-2950, 2002

9. Cox ME, Gleave ME, Zakikhani M, Bell RH, Piura E, Vickers E, Cunningham M, Larsson O, Fazli L and Pollak M: Insulin receptor expression by human prostate cancers. Prostate 96: 33-40, 2009.

10. Law JH, Habibi G, Hu K, Masoudi H, Wang MY, Stratford AL, Park E, Gee JM, Finlay P, Jones HE, et al: Phosphorylated insulin-like growth factor-i/insulin receptor is present in all breast cancer subtypes and is related to poor survival. Cancer Res 68: 10238-10246, 2008.

11. DeVita VT: Dose-response is alive and well. J Clin Oncol 4: 1157-1159, 1986.

12. Minden A and Karin M: Regulation and function of the JNK subgroup of MAP kinases. Biochim Biophys Acta 1333: F85-104, 1997.

13. Johnson GL and Lapadat R: Mitogen-activated protein kinase pathways mediated by ERK, JNK, and p38 protein kinases. Science 298: 1911-1912, 2002.

14. Kyriakis JM, Banerjee P, Nikolakaki E, Dai T, Rubie EA, Ahmad MF, Avruch J and Woodgett JR: The stress-activated protein kinase subfamily of c-Jun kinase. Nature 369: 156-160, 1994.

15. Li-Weber M: New therapeutic aspects of flavones: The anticancer properties of Scutellaria and its main active constituents Wogonin, Baicalein and Baicalin. Cancer Treat Rev 35: 57-68, 2009.

16. Livak KJ and Schmittgen TD: Analysis of relative gene expression data using real-time quantitative PCR and the 2(-Delta Delta C(T)) method. Methods 25: 402-408, 2001.

17. Osborne CK, Bolan G, Monaco ME and Lippman ME: Hormone responsive human breast cancer in long-term tissue culture: Effect of insulin. Proc Natl Acad Sci USA 73: 4536-4540, 1976.

18. Hanahan D and Weinberg RA: Hallmarks of cancer: The next generation. Cell 144: 646-674, 2011.

19. Crescenzi E, Chiaviello A, Canti G, Reddi E, Veneziani BM and Palumbo G: Low doses of cisplatin or gemcitabine plus Photofrin/photodynamic therapy: Disjointed cell cycle phase-related activity accounts for synergistic outcome in metastatic non-small cell lung cancer cells (H1299). Mol Cancer Ther 5: 776-785, 2006.

20. Weston CR and Davis RJ: The JNK signal transduction pathway. Curr Opin Genet Dev 12: 14-21, 2002.

21. Arcidiacono B, Iiritano S, Nocera A, Possidente K, Nevolo MT, Ventura V, Foti D, Chiefari E and Brunetti A: Insulin resistance and cancer risk: An overview of the pathogenetic mechanisms. Exp Diabetes Res 2012: 789174, 2012

22. Weroha SJ and Haluska P: The insulin-like growth factor system in cancer. Endocrinol Metab Clin North Am 41: 335-350, 2012.

23. Ichijo H: From receptors to stress-activated MAP kinase. Oncogene 18: 6087-6093, 1999.

24. Bogoyevitch MA: The isoform-specific functions of the c-Jun $\mathrm{N}$-terminal Kinases (JNKs): Differences revealed by gene targeting. Bioessays 28: 923-934, 2006. 